Portland State University

PDXScholar

Summer 8-9-2019

\title{
Relationship Between Empathy and Language Proficiency in Adult Language Learners
}

\author{
Mika Sakai \\ Portland State University
}

Follow this and additional works at: https://pdxscholar.library.pdx.edu/open_access_etds

Part of the Bilingual, Multilingual, and Multicultural Education Commons, and the First and Second Language Acquisition Commons

Let us know how access to this document benefits you.

\section{Recommended Citation}

Sakai, Mika, "Relationship Between Empathy and Language Proficiency in Adult Language Learners" (2019). Dissertations and Theses. Paper 5155.

https://doi.org/10.15760/etd.7031

This Thesis is brought to you for free and open access. It has been accepted for inclusion in Dissertations and Theses by an authorized administrator of PDXScholar. Please contact us if we can make this document more accessible: pdxscholar@pdx.edu. 


\title{
Relationship Between Empathy and Language Proficiency in Adult Language Learners
}

\section{by}

\section{Mika Sakai}

\section{A thesis submitted in partial fulfillment of the} requirements for the degree of

\author{
Master of Arts \\ in \\ Teaching English to Speakers of Other Languages
}

Thesis Committee:

Lynn Santelmann, Chair

Kimberley Brown

Steven L. Thorne

Portland State University

2019 
C2019 Mika Sakai 


\begin{abstract}
This study reviews concepts and the mechanism of empathy, and the relationship between empathy and language proficiency, focusing on the aspect of cognitive empathy. It also discusses whether empathy levels could be developed by learning language to a highly proficient level. I compared the empathy levels between high and low proficiency second-language learners to determine if there was correlation between empathy and other factors such as gender, studying abroad, education background, and usage of a second language. I found that there was no relationship between empathy level and language proficiency level; however, there was one between empathy and gender. For further research, I suggest continuing studies in executive function in adults, especially adult bilinguals (including highly proficient second language learners), and to investigate how executive function in adults influences behavior and empathy development.
\end{abstract}




\section{Acknowledgements}

I would like to say thank you to the faculty members at the Applied Linguistics Department who guided me to this point. Finally, I figured out what I wanted to do and what I wanted to be. You are all my inspiration. Your knowledge, experiences, and passion showed me where I should go.

First of all, to my advisor, Dr. Lynn Santelmann: thank you. It is hard to express my gratitude to you in words. Your encouragement, patience and belief in me made me complete this thesis. As you may remember, the first time I took a course with you, I had been struggling to catch up in the class and pass quizzes. Thank you from my heart not to give up on me. I am truly honored to work on my thesis with you and really enjoyed our conversation, especially about bilingualism.

I truly appreciate my committee members, Dr. Kimberley Brown \& Dr. Steven L. Thorne. Without the two of you I could not even start writing a thesis. You are the reason I decided to write a thesis and pursue my profession as a linguist. Your energy and sincerity always keep me moving forward.

Dr. Nike Arnold, Dr. Tucker Childs, Dr. John Hellermann, Dr. Alisa Hartig, Dr. Tanya Sydorenko, Dr. Jenny Mittelstaedt, Dr. Susan Conrad, Practicum instructor Regina Weaver, and my dear friend and our leader of Activist Applied Linguistics, Janet Cowal, thank you. I learned a lot from all of you. 
I would like to express my sincere gratitude to all my research participants, and my friends who reached out to their friends and acquaintances to ask them to participate in my research. Without their support, I could not even collect the data for my research.

Lastly, I would like to give my sincere gratitude and appreciation to my husband. Without his support, I could not even have continued studying. Thank you for understanding me even though what I am doing is not our cultural norm. Also to my children, my sister, my father, and my late mother, thank you for being there for me. I love you all. 


\section{Table of Contents}

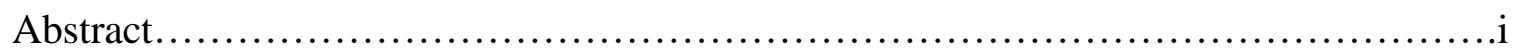

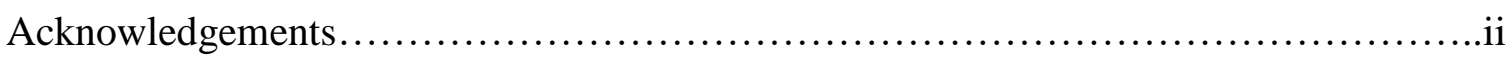

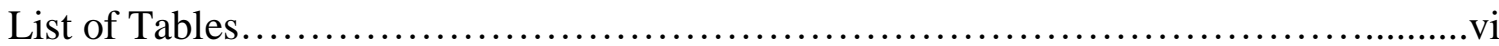

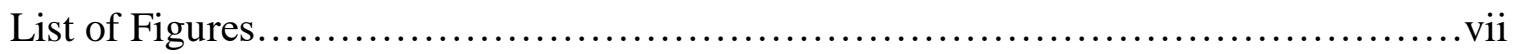

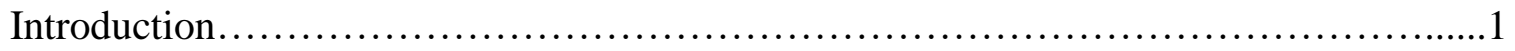

Literature Review.................................................................

Global citizenship and intercultural competence.............................4

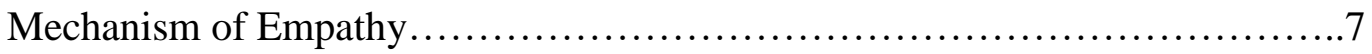

Language Learning and Cognition ...........................................11

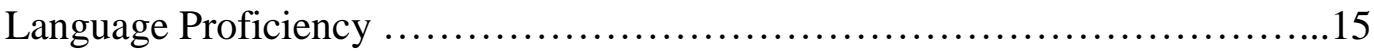

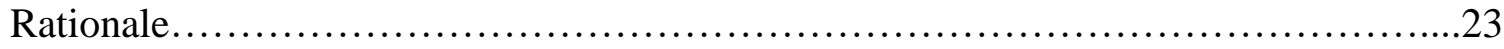

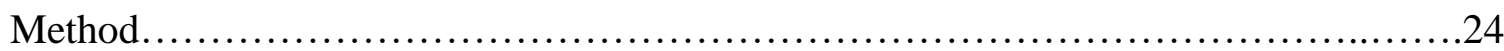

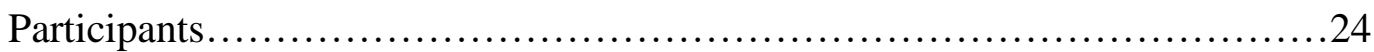

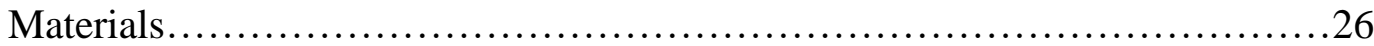

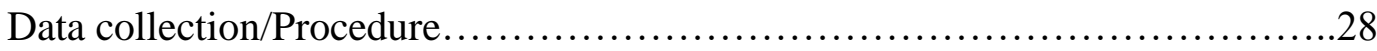

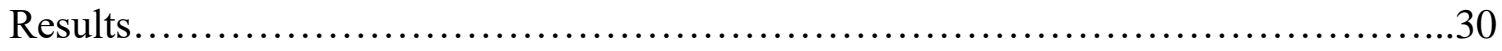

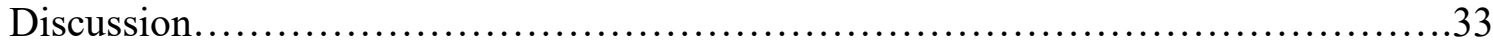




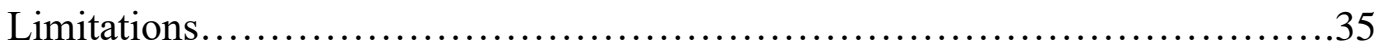

Suggestions for future research..................................... 37

Conclusion...................................................... 38

References...............................................................40

Appendix A: Language History Questionnaire (Modified by Mika Sakai)...............49

Appendix B: S. Baron-Cohen and S. Wheelwright, (2004) Empathy Quotient with

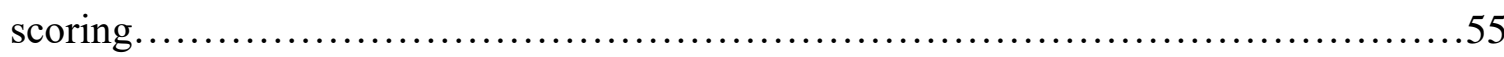




\section{List of Tables}

Table 1: Comparison between ACTFL \& CEFR ...................................20

Table 2.1: First and second languages of participants in order of frequency.............23

Table 2.2: Age of participants.....................................................

Table 2.3: Highest education level of participants.................................

Table 3.1: Mean empathy scores by proficiency score............................29

Table 3.2: Means of total Empathy Quotient (EQ) score across genders..................30 


\section{List of Figures}

Figure 1: Ice Cream Cone Representation of ACTFL proficiency levels...............15 


\section{Introduction}

Explaining the reason I chose this topic for my thesis research requires me to talk about myself, an immigrant and a bilingual woman, and a member of minority in the monolingual society of the United States. It is very personal and it may not be common as an academic researcher, but it is true that my story is my absolute motivation to become a linguist and a researcher. I am not a native speaker of English and am from a different county, which might make the readers imagine how I look, how I talk, and how I communicate. I have been learning my second language, English, for a long time, and trying to be a perfect English speaker like other Americans. I only taught English to my children because I believed one of the bilingual myths: that teaching two languages makes children confused and will negatively affect their learning development. I tried my best to assimilate myself and my family into the American society as Americans, and left my original culture somewhere in a place of culturally and socially controlled dominant society. I regret that I did not teach my own culture and language to my children because I finally realized that it was a part of my identity, and my family should know about it as our family culture. If I had known that my culture was important as well as the dominant culture and if someone at least tried to understand how I felt as a female bilingual immigrant, staying beside me, it would have made a difference in my

life. We need empathy to those who do not have social, cultural, and economic power in the society. Those vulnerable people who lack power are called a marginalized population, a minority group, colored people, non-native speakers, immigrants, refugees, 
LGBTs, disables, low-income families, non-Christians, etc. How do we as human being understand other people's feelings and share their pain?

As a linguist, I believe that it is natural that there are differences between people who speak different languages and have different cultures. However, some people think that we all are fundamentally the same human beings. It is dangerous that people see things and try to solve problems from a base of similarity. We are different, which is fine. We should understand, accept, and respect differences, and find a way to reduce or remove a conflict. In order to find a way of understanding the differences, I focused on one of the human behaviors, empathy, which could be developed by human cognition.

The primary goal of this study is to understand about empathy and examine empathy in two groups of the people: those who speak a second-language fluently and those who are at a beginning level of the language, and to find out if different levels of language proficiency will correlate to different levels of empathy. If a person who has the advanced language skills has a higher level of empathy, but a beginning learner has lower empathy, language learning could be a significant tool to increase empathy. In addition, this thesis discusses the relationship between executive function and empathy level. Moreover, summarizing language proficiency is included to help the readers to understand the characteristics of each language proficiency level. The research might also help to raise awareness that language learning is key for learning about humanity: understanding who we are, learning about each other, and caring about each other. A more empathetic person is more likely to succeed in being a global citizen who is passionate about social justice, economic justice, human rights, linguistic rights, and 
global ethics (Jackson, 2014). It is imperative in this diverse dynamic society that we have the quality of global citizenship in order to find a mutual collaborative solution to the problems that we have. 


\section{Literature Review}

In order to study what language learning is, and discuss whether there is a possible correlation between language proficiency and empathy development, the literature review discusses four topics: global citizenship and intercultural competence, mechanism of empathy, language learning and cognition, and language proficiency.

\section{Global citizenship and intercultural competence}

The words, "global" and "global citizenship" are seen or heard more frequently than ever, and they appear to be in the media, academia, and even in daily conversation. However, who really understands the meaning of global citizenship, and how to become a global citizen?

According to Jackson (2014), there are three core components to global citizenship: social responsibility, global competence, and global civic engagement. Social responsibility is the perceived level of interdependence and social concern for others such as social and environmental issues; global competence is having an openminded attitude while actively seeking to understand others' cultural norms and expectations and leveraging this knowledge to interact and communicate effectively outside one's comfort zone. Global civic engagement is the actual participation and action in the local, state, national and global community issues such as volunteerism, political activism, and community participation. In order to become a true global citizen, there is much more than just traveling to foreign countries and studying about their cultures; being a true global citizen is more focused on an individual commitment to 
think about and reflect on what an individual can do and will do toward finding possible solutions for the conflict between people. This reflection process could be a meaningful start to solving problems caused by people's differences.

Although globalization is often discussed in connection with capitalism and neocolonialization in a negative manner, I would like to focus on the positive side of globalization: the awareness of differences, the recognition of differences, and the mutual respect as human beings that can result from interactions with people from other countries. Particularly I would like to discuss intercultural competence more because intercultural competence plays a significant role in being a global citizen.

Jackson (2014) notes several widely-known models of Intercultural Competence such as Byram's (1997) intercultural communicative competence model, Chen and Starosta's (2008) intercultural communication model, M.J. Bennett's (1993) intercultural sensitivity development model, and Deardorff's (2006) intercultural competence process model. Each model has a slightly different name because it is difficult to define the meaning of intercultural competence and name it. However, these models contain several common themes, which are: collecting knowledge of another culture, self-awareness, developing communicative skills, and transformation. Jackson (2014) also states that M. J. Bennett's DMIS (Developmental Model of Intercultural Sensitivity) has had a significant impact on this field. According to M. J. Bennett $(1986,1998)$, there are six stages of intercultural sensitivity, or a transformation from ethnocentrism to ethnorelativism: denial, defense, minimization, acceptance, adaptation and integration. At the denial stage, people do not perceive cultural difference; at the defense stage, they 
have more ability to perceive the difference, but they attach negative stereotypes to it. They look at their culture as the peak of development, whereas they look at other cultures as underdeveloped. People at minimization try to bury cultural differences under the belief that all people are essentially the same because they are just human. The stage of acceptance represents a shift from ethnocentrism to ethnorelativism. People at that stage recognize and respect other cultures; however it does not mean that they have to agree with or take on those different perspectives. It is more like knowing there are some other valuable things in the world beside their own cultures. People at the adaption stage allow their behavior and perspective applying to their own culture and others to shift into a different cultural frame, considering how power is being exercised within a cultural context. The most common forms of adaptation are biculturalism/multiculturalism and empathy. M. J. Bennet (1986) defines empathy as a temporary shift that one mentally perceives events as if one were the other person in a certain situation. Bennet interprets biculturalism/multiculturalism as an ability to shift into two or more cultural worldviews in the cross-cultural context. People at the last stage of integration interpret and evaluate behavior from a variety of cultural frames of reference and engage in contextual evaluation, so that there is no right or wrong answer. Clearly, no matter what stages a person has been through, increasing intercultural competence is based on a cognitive learning process: reflecting and understanding difference, and feeling other's feelings. Based on this theoretical framework, DMIS, M. J. Bennett, Hammer \& Wiseman (2003) developed the Intercultural Development Inventory (IDI). According to the Intercultural Development Inventory website (2019), the IDI is the premier cross-cultural assessment 
of intercultural competence, and is used by thousands of individuals and organizations to build intercultural competence.

According to J. M. Bennett (2014), in order to develop intercultural competence, a person needs to focus on three competencies: cognitive competency such as cultural selfawareness, affective competency such as curiosity, and behavioral competency such as empathy. She claimed that empathy is a behavioral skill and stated that it is "the imaginative intellectual and emotional participation in another person's experience" (pp.7). I do not agree that empathy is only a behavioral skill. I believe that empathy is multi-dimensional; it has layers of definition and function, and it is a process of cognitive and behavioral learning, stimulating emotion and possibly leading to positive action. Regardless of the definition, empathy is key for intercultural competence. Without an empathetic learning process, there can be no mutual understanding between people; there are no collaborative solutions. Therefore, it is crucial to study empathy and understand the mechanism of empathy.

\section{Mechanism of Empathy}

Generally speaking, empathy is the ability to understand other people's feelings and thoughts as if you are in the same situation; however, it is extremely difficult to define a decontextualized, universal sense of empathy because many concepts of empathy have been claimed by people from different academic fields. As an overview of the mechanism of empathy, there are two major components in order to understand and measure empathy: affective empathy and cognitive empathy. Walter (2012) also suggests there could be a genetic component to affect empathy; however, I will not discuss this 
aspect further because it is beyond the scope of this study. According to Walter (2012), affective empathy might be based on emotional mimicry, which can be defined as automatic synchronization of emotional behavior, or emotional contagion where people experience emotions similar as those of others. For example, people feel excited when they are surrounded with people who are excited or even cry when they watch a sad movie. However, it does not mean that emotional cognition influences their perspective. Another major component, cognitive empathy refers to theory of mind, the ability to represent and understand the mental states of others in general, but also not necessarily influencing affective state. Here the mental states include beliefs, desires, or intentions but also emotions and affective states, and therefore, affective empathy and cognitive empathy overlap (Walter, 2012). Empathy is a multidimensional and complex phenomenon and can not be seen only as a characteristic of individual constructions. It is a complex process that takes place in the interaction between people and constantly being renegotiated (Herlin \& Visapaa, 2016).

Evaluating empathy levels is another major topic in this research. Empathy has been actively discussed recently, and multiple research articles related to empathy have been published (Dewaele \& Wei, 2012; Gruhn, Rebucal, Diehl, Lumley \& LabouvieVief, 2008; Herlin \& Visapaa, 2016; Vossen, Piotrowski \& Valkenburg, 2015; Walter, 2012; Zelazo, Blair \& Willoughby, 2016). There are many organizations that study and practice empathy in different ways. Roots of Empathy, one of these non-profit organizations focusing on the research of empathy also has a mission to build caring, peaceful, and civil societies through the development of empathy in children and adults. 
Zelazo (2014) who was a keynote speaker for Roots of Empathy research symposium in 2014 addressed the topic of executive function and implications for promoting empathy in childhood. He claimed that high executive function in childhood would lead to developing skills such as paying attention, resisting distractions, keeping relevant aspects of the context in mind, flexibility in considering others' perspectives, and inhibiting avoidance responses, and consequently learning how to behave empathetically. Executive function skills are the attention-regulation skills that sustain attention, keep goals and information in mind, refrain from responding immediately, resist distraction, tolerate frustration, consider the consequence of different behaviors, reflect on past experiences, and plan for the future (Zelazo, Blair \& Willoughby, 2016). According to Zelazo (2014), three aspects of executive function: cognitive function, working memory and inhibition control will influence the development of empathy, and so that the level of executive function in childhood could predict the level of self-social awareness, school readiness, academic achievement and other outstanding development into adulthood. Moreover, he suggests that the interventions on those executive function skills integrated with reflection practice help to develop empathy in children. Executive function develops during early childhood and could provide a foundation for children's empathy development and empathetic behavior (Zelazo, 2014).

Zelazo's hypothesis has led me to hypothesize that the bilingual children who have higher executive function would have higher empathy levels, and that learning more than one language could be the most salient factor in order to increase empathy. On the other hand, there is an alternative hypothesis, given in a longitudinal study about the 
relationship between empathy and personal and social interactions of the participants, age from 10 years to 87 years (Gruhn, Rebucal, Diehl, Lumley \& Labouvie-Vief, 2008). That study shows that the participants' positive attitudes or thoughts toward social interactions are influential in empathy development. It is possible that language use or language learning is not a relevant factor in empathy development, but general social interaction is.

Empathy might be developed through social interaction, which can be observed in conversation. Herlin and Visapaa (2016) examined empathy with conversation analysis and cognitive grammar to find a deeper understanding of how empathy would take a place in real-life conversations. In conversation analysis, not only the words themselves but also speaker's physical movements, prosody and pauses are examined. In cognitive grammar, the "ground", which represents a speech event including place, time and even speaker's knowledge, is examined as well. It is important how speakers construe the ground: symmetrically or asymmetrically. A symmetrical environment gives more empathetic feelings to speech participants. For example, if first pronoun, "I", is used in a sentence, it means that a speaker still talks about "I" using an asymmetrical ground, not talking to interlocutor at the same level of ground. Instead, if focusing more on the topic without using first pronoun, it is more open for sharing information and understanding (Herlin \& Visapaa, 2016) using a symmetrical ground. This analysis indicates that how much empathy is involved in better communication and how language is used to show empathy. 


\section{Language Learning and Cognition}

The more common global citizenship becomes, the more common diversity becomes. Diversity creates conditions for people to interact with people from different places more frequently, and more opportunities to communicate with people who speak different languages. It is natural that people consider learning another language besides their native language for better communication in a diverse society, and try to be proficient in that language.

People realize that language plays an important role in communication; without communication, there would be no negotiation, mutual understanding and problem solving. Although people may understand the meaning of language, they may not understand what language truly is, how language is produced, and how people acquire their languages. Encyclopedia Britannica (Britannica, n.d.) states the following meaning of language:

Language, a system of conventional spoken, manual, or written symbols by means of which human beings, as members of a social group and participants in its culture, express themselves. The functions of language include communication, the expression of identity, play, imaginative expression, and emotional release.

It is clear that language is an abstract system because it is composed of symbols that express human beings' imagination, emotion and thoughts. It is created internally, by mind, which is a part of brain function, and could be defined as a 
combination of three main cognitive factors: perception, memory, and consciousness (Perlovsky \& Sakai, 2014). Once words are uttered, they return to mind, where they are understood, and the cycle from the mind to the language and then from the language to the mind. This recursiveness shows that there is the relationship between language and cognition (Perlovsky \& Sakai, 2014). In order to understand that relationship, we need to have an overview the history of language learning.

In the history of language learning, Chomsky's theory, Universal Grammar started as a reaction to Skinner's Behaviorism theory: the human mind is involved in deep processing of meaning rather than in memorized responses to environmental stimuli (Moeller \& Catalano, 2015). Chomsky claimed that human beings are biologically programmed for language and have an innate ability to develop the grammatical system as an internal thinking-learning process (Moeller \& Catalano, 2015). After Chomsky's theory, multiple theories focusing on human cognition and the learning process emerged, though many do not assume language is biologically programmed. Among these theories, Sociocultural Theory (hereafter SCT) uniquely emphasizes human cognition in the relationship to others including social, cultural and historical elements (Ortega, 2007). The SCT is based on a Russian psychologist Vygotsky's theory, and his research was inspired by three essential principles of Marxist theory: 1) human consciousness is fundamentally social; 2) human activity is mediated by material artifacts and psychological and symbolic tools/signs; 3) analysis of human activity and 
development should be holistic (Lantolf, Thorne \& Poehner, 2015). In Vygotsky's framework, mediation increase cognitive development using physical tools and symbolic artifacts such as language, literacy, numeracy, categorization, rationality, logic, etc. (Lantolf, Thorne \& Poehner, 2015). For example, one of Vygotsky's studies showed that children who initially remembered a list of words poorly were able to memorize them better when they used picture cards to mediate their remembering process (Eun \& Lim, 2009). Another main concept, internalization is a negotiated learning process, in which an individual creates his or her own understanding by mediation. An individual reorganizes the relationship of the individual to her or his social environment (Winegar, 1997, as cited in Lantolf \& Thorne, 2007) learning how to plan, categorize, evaluate a situation and consider alternatives, and imagine possible outcomes (Lantolf, Thorne \& Poehner, 2015). Mediation and internalization are closely integrated within SCT. In other words, the semiotic process that helps human consciousness, develops through interaction with artifacts, tools, and social others in an environment, and results in individuals finding new meanings in their world (Yamagata-Lynch, 2010). People's building a certain kind of semantic system inside themselves through the interaction with others will influence the linguistic cognition, and the contextual materials created by social and cultural interactions will increase the level of language learning. It is very common that language learners often use inappropriate words or phrases because they learn them only from the dictionary, not from authentic usage in the real situations or interactions. 
In addition to the cognitive and linguistic aspects, there are some important nonlinguistic factors that might influence the language learning process: motivation, attitudes, anxiety (Ganschow et al., 1994) and beliefs (Huang \& Tsai, 2003).

Historically, motivation has been researched from four major perspectives: the socialpsychological framework discusses the social context of SLA and attitudes and relations between different communities; the cognitive-situated analysis focuses on the L2 learning in the specific learning settings like classroom; the process-oriented motivation approach conceptualizes two aspects: motivation to engage in L2 learning and motivation during engagement. Although it is difficult to measure motivation objectively because the research mainly relies on self-report data, the research provides empirical confirmation that some strategic practice influences student motivation positively (Ushida \& Dornyei, 2012). The motivational strategies could be based on cultural, contextual, environmental and even personal elements; however, in spite of those findings, there is no strong evidence for how to help language learners maintain motivation (Ushida \& Dornyei, 2012).

Anxiety is another difficult element to measure and it also difficult to determine how it influences language learning process. Ganschow et al. (1994) states that high proficiency learners have less anxiety and lower proficiency learners have more anxiety, and according to Huang \& Tsai (2003), advanced learners have more positive beliefs toward language learning. That research predicts that how to set up an individual attitude toward learning language might affect the progress of language learning. 
Defining language learning and conceptualizing language development is complex and difficult due to multiple aspects and factors that involved with language learning. However, in order to understand which factors contribute to language learning and define the levels of language learners, evaluating their skills and performances by a certain standard is necessary.

\section{Language Proficiency}

Assessing how a learner perceives sounds, comprehends the meaning, produces sentences and communicates with others is difficult and complex, and in order to succeed in assessing language ability, certain guidance might be helpful.

There are two world-wide known organizations who create proficiency guidelines to evaluate learners' functional language ability: The American Council on the Teaching of Foreign Languages (ACTFL) and the Council of Europe. ACTFL first published the ACTFL Proficiency Guidelines in 1986 and currently the 2012 version is available. The Council of Europe updated Common European Framework of Reference (CEFR) for Languages: Learning, teaching assessment in 2018. Both of these frameworks divide proficiency levels according to different linguistic skills: speaking, writing, listening and reading, and CEFR scales are divided by more specific situations or tasks. In the United States, the ACTFL Guidelines have been used as an important assessment tool on language teaching and learning for the past 25 years (ACTFL, 2012). 


\section{ACTFL guidelines}

The ACTFL Guidelines are descriptions of what individuals can do with language in terms of speaking, writing, listening, and reading in real-world situations in a spontaneous and non-rehearsed context (ACTFL, 2012). For each skill, there are five major levels of proficiency: Distinguished, Superior, Advanced, Intermediate, and Novice, and the major levels Advanced, Intermediate and Novice are subdivided into High, Mid, and Low sublevels (ACTFL, 2012. See Figure 1.).

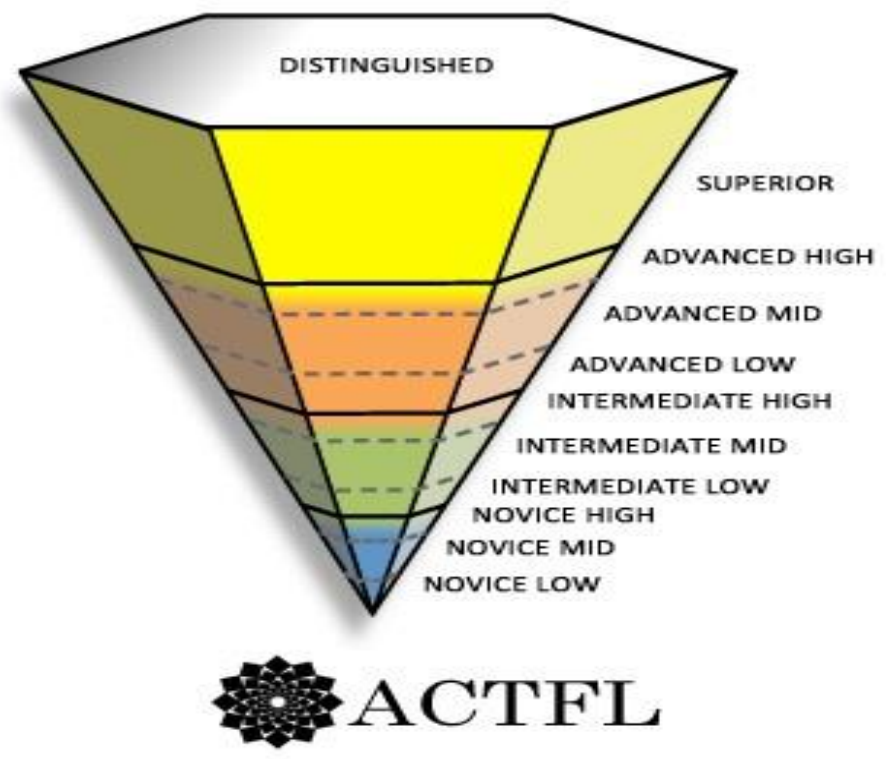

Figure 1: Ice Cream Cone Representation of ACTFL proficiency levels

According to ACTFL (2012) guidelines, learners at the Distinguished level are able to speak, read, write, and understand language skillfully, and with accuracy, efficiency and effectiveness. They are educated and articulate language users. They can reflect on a wide range of global issues and highly abstract concepts in a culturally 
appropriate manner, using persuasive and hypothetical discourse for representational purposes. They still have a non-native accent, an occasionally there are small errors. Basically they can manage the language in any situations they find themselves in.

Learners at the Superior level are able to communicate with accuracy and fluency on a variety of topics including social and political issues and even abstract concepts, employing a variety of interactive and discourse strategies, such as turn-taking and separating main ideas from supporting information through the use of syntactic, lexical and phonetic devices. They may occasionally make errors, particularly in low-frequency structures and in complex high-frequency structures, which does not disturb the native interlocutor during conversation. They are generally aware of the artistic properties of language and of its literary styles, but may not fully understand texts in which cultural references are deeply embedded.

Learners at the Advanced levels are able to manage language in different skills fully and their accuracy may depend on their interests and subjects. This level is divided into High, Medium and Low. The higher their level becomes, the more abstract and complex subjects they can handle, and the more complex grammatical structures and the more vocabulary they can use. They are able to handle with ease and confidence a large number of communicative tasks such as work, school, home and leisure activities as well as topics relating to events of current, public and personal interest or individual relevance.

As well as the Advanced level, the Intermediate level is also divided into three sublevels: High, Medium and Low. Learners at these levels are more likely to handle 
language with their familiar topics related to their daily life asking and responding to simple questions with short and simple sentences. Due to the limited knowledge of vocabulary and structure, there might be misunderstanding, and pauses, reformulations, and self-corrections. The Low sublevel might struggle to find appropriate questions and answers in appropriate grammatical form with hesitancy and inaccuracies, and their pronunciation, vocabulary and grammar are strongly influenced by their first language.

The Novice level learners are able to manage successfully uncomplicated communicative tasks related to highly predictable, basic everyday topics that affect them directly. They use short simple words and phrases that they have learned and memorized. They also may rely on their own background knowledge and extralingustic support to derive meaning. Again, the sublevels of High, Mid and Low Novice depend on how much speakers can create complete sentences to succeed in communication. They may often be misunderstood or not understood at all because of their insufficient ability to use words appropriately. The Novice Low learners have no real functional ability, and probably their speech may not be intelligible; however, they may be able to exchange very basic information such as name, and they can at least copy or transcribe familiar words or phrases.

\section{CEFR guidelines}

On the other hand, the CEFR guideline has three levels of learners (called "users" in their framework): Basic user, Independent user and Proficient user, and each level has two sub levels: A1 \& A2 under Basic user, B1 \& B2 under Independent user, and C1 \& C2 under Proficient use. Therefore, the framework starts from A1 as the lowest level and 
goes through C2 as the highest level. There are two major parts of the scale: common reference levels and illustrative scales. Under the common reference levels, there are subsections, which are global scale, self-assessment grid, and qualitative aspects of spoken language use, and the illustrative scales have four different categories that will be described later.

In the global scale, which is a more general descriptive scale, Proficient users can understand everything heard or read, summarize information from different spoken and written sources, express themselves spontaneously, very fluently and precisely. Independent users can understand the main ideas of complex text on both concrete and abstract topics, but may not detailed information. Basic users are able to understand sentences related to very basic personal and family information, shopping, local geography, and employment, and communicate and describe in simple and routine tasks. They can interact with others when the interlocutors talk slowly and clearly with understood and helpful attitudes.

In the qualitative aspects of spoken language use, learners of each level are described by five aspects: range, accuracy, fluency, interaction, and coherence. C2 \& C1 users show great flexibility reformulating ideas in different linguistic forms, emphasizing, differentiating concepts and eliminating ambiguity; however, $\mathrm{C} 1 \mathrm{might}$ lose a natural flow when speaking on conceptual difficult subjects. B2 \& B1 users have a sufficient range of language to give clear descriptions, express viewpoints on most general topics without noticeable searching for words or errors. B1 users may have some hesitation and circumlocutions even when they talk about their familiar topics and interests. Both A2 \& 
A1 users are at the very beginning level, and are able to communicate with others in simple everyday situations using basic sentence patterns with memorized phrases and groups of a few words. They can link groups of words with simple connectors such as "and", "but", "then" and "because", and still make basic mistakes. A1 users speak with more pauses, repetition, repair and mistakes.

Under illustrative scales, there are four categories: Communicative activities, Communication Strategies, Working with text, and Communicative Language Competence. I cannot describe the details for each situation here. However, overall, C2 users have no difficulty in any form of spoken and written language; $\mathrm{C} 1 \mathrm{~s}$ have a high ability to understand most of the speech and texts on a variety of topics; B2s also understand a wide range of speech and texts but only in standard dialect at normal speed; B1s understand straightforward factual texts about common daily topics, not abstract topics; A2s understand simple short statements when speaking slowly and clearly; and A1s can follow very slow and carefully articulated speech and texts on the topics related to their immediate needs, especially with visual support. The higher their proficiency becomes, the more socially competent they become. They appropriately handle the cultural and social situations with native speakers, and they are familiar with the native speakers' culture and are aware of the differences between native speakers' culture and their own culture.

Comparing two major language proficiency assessment, ACTFL emphasizes on assessing the learners who study languages more for academic purpose, whereas CEFR is based on actual tasks, and explains how learners can or can not use language under 
certain situations. It is focused more on communicative fluency in everyday life. There is a comparison table adopted by Assigning CEFR Ratings to ACTFL Assessments below (Table 1.)

Table 1. Comparison between ACTFL \& CEFR (adopted by Assigning CEFR Rating to ACTFL Assessment, ACTFL)

\begin{tabular}{|c|c|c|c|}
\hline \multicolumn{2}{|c|}{$\begin{array}{c}\text { Receptive Skills - Reading and } \\
\text { Listening }\end{array}$} & \multicolumn{2}{|c|}{$\begin{array}{c}\text { Productive Skills - } \\
\text { Speaking and Writing }\end{array}$} \\
\hline ACTFL & & ACTFL & CEFR \\
\hline Distinguished & $\mathrm{C} 2$ & & \\
\hline Superior & C1 & Superior & $\mathrm{C} 2$ \\
\hline Advanced High & C1 & Advanced High & $\mathrm{C} 1$ \\
\hline Advanced Mid & B2 & Advanced Mid & B2 \\
\hline Advanced Low & B1 & Advanced Low & B2 \\
\hline Intermediate High & B 1 & Intermediate High & B 1 \\
\hline Intermediate Mid & A2 & Intermediate Mid & B 1 \\
\hline Intermediate Low & A1 & Intermediate Low & A 2 \\
\hline Novice High & A1 & Novice High & A 1 \\
\hline Novice Mid & & Novice Mid & \\
\hline Novice Low & & Novice Low & \\
\hline
\end{tabular}

Highly proficient learners can use the language in culturally appropriate ways, whereas low-level learners struggle with it. High proficient speakers are sensitive to linguistic and cultural differences of the language, and this ability might reflect greater 
empathy and cultural understanding. Therefore, it is possible that highly proficient learners will demonstrate higher empathy than low-level learners. 


\section{Rationale}

Including Zelazo's research, the majority of research about executive function, language learning, and empathy development has focused on children, but not adults. Zelazo's findings support the idea that bilingual children who have higher executive function are more likely to develop empathy. If executive function, developed through using more than one language, is an influential factor for empathy development in children, then older language learners who have achieved a high language proficiency might become more empathetic when compared to people who have never studied language or who have low second language proficiency. This means that language proficiency could play an important role in the development of empathy.

Based on this, I hypothesize that people who are advanced in language learning will have higher level in empathy test than the beginner language learners have, and language proficiency may influence empathy development. 


\section{Method}

This research is a basic, confirmatory research based on a quantitative data from survey scores. I compared the scores on an empathy questionnaire between two groups with different language proficiency: advanced language learners and beginning language learners, to determine whether there is statistically any significant difference in empathy level between the two groups.

\section{Participants}

83 language learners participated in this survey. Originally, there were 87 people who answered the questions, but four people were deleted because of their inadequate answers. 47 participants had English as their primary language and studied a language other than English, while 35 participants studied a language other than English as their primary language. One participant chose both English and other language as his primary languages (Table 2.1). The participants were a mixture of different types of language learners with different backgrounds. The majority of the participants were at the age range of over 30 years old (Table 2.2) and had completed higher education, and some even had a PhD degree (Table 2.3.). Because of my social network and educational environment, most participants have higher education experiences. 
Table 2.1: First and second languages of participants in order of frequency (Total number of participants: 83 )

\begin{tabular}{|l|l|l|l|}
\hline $\mathbf{1}^{\text {st }}$ Language & $\begin{array}{l}\text { Number of } \\
\text { participants }\end{array}$ & $\mathbf{2}^{\text {nd }}$ Language & $\begin{array}{l}\text { Number of } \\
\text { participants }\end{array}$ \\
\hline English & 47 & English & 26 \\
\hline Japanese & 15 & French & 17 \\
\hline Spanish & 4 & Spanish & 16 \\
\hline Arabic & 5 & German & 7 \\
\hline German & 3 & Japanese & 4 \\
\hline Other & 9 & Arabic & 1 \\
\hline & & Other & 12 \\
\hline
\end{tabular}

Table 2.2: Age of participants (Total number of participants: 83)

\begin{tabular}{|l|l|l|l|}
\hline Age & $\begin{array}{l}\text { Number of } \\
\text { participants }\end{array}$ & Gender & $\begin{array}{l}\text { Number of } \\
\text { participants }\end{array}$ \\
\hline Age 15-20 years old & 3 & Male & 21 \\
\hline Age 21-30 years old & 22 & Female & 58 \\
\hline Age 31-40 years old & 21 & Other & 4 \\
\hline Age 41-55 years old & 33 & & \\
\hline Age Over 56 years old & 4 & & \\
\hline
\end{tabular}

Table 2.3: Highest education level of participants (Total Number of participants: 83)

\begin{tabular}{|l|l|}
\hline Highest Education completed & Number of participants \\
\hline High School & 6 \\
\hline 2-year College & 7 \\
\hline 4-year College & 28 \\
\hline Master & 32 \\
\hline $\mathrm{PhD}$ & 7 \\
\hline Other & 3 \\
\hline
\end{tabular}




\section{Materials}

I used two measures: The Language History Questionnaire (LHQ) and the Empathy Quotient. The LHQ measured the level of language proficiency and the EQ measured the level of empathy.

The Language History Questionnaire (LHQ 1.0) was developed by Li, Sepanski \& Zhao (2006) as a base questionnaire to assess language proficiency and use for bilinguals and language learners. It was created based on their analyses of 41 published Language History questionnaires, which gives it a certain degree of validity since those 41 questionnaires had been used by many researchers (Li, Sepanski, \& Zhao, 2006). Before distributing the questionnaire to the participants of my survey, I modified it by deleting the questions regarding accent because I wanted to focus on how language learners use their languages to accomplish different communicative tasks for different purposes. Particularly for an advanced group, even though they might not be able to speak like native speakers, as long as they can communicate with others and accomplish tasks in their second languages, I considered their communicative skill to be at a high level. I wanted to focus on their skill for communicating with others to have social interactions in their L2s and ability to be involved in the society as a community member. I also removed some questions because they were questions related to their previous backgrounds such as when they have emigrated or whether they were living in a second language speaking country in their childhood, which were not relevant for this research.

My version of modified Language History Questionnaire (Appendix A) had 26 short-answer questions, including some extra questions such as age, gender and highest 
educational level. The questions asked which language the participants used in different domains and with different interlocutors; for example, which language do you speak at home? which language do you use for school activities? which language do you use when you read book/newspaper? The survey also asked participants to rate their different language skills such as listening, speaking, reading and writing in their L2 on a scale from 1 (low) to 7 (high). The groups were divided into advanced language learners and low-level students mainly based on their self-rated level of these skills because they are most relevant to see the difference in language proficiency. The ones higher than 6 are considered advanced speakers, while the ones lower than 3 are considered low-level speakers.

For empathy survey, I used the Empathy Quotient (EQ) developed by BaconCohen \& Wheelwright (2003), which is considered the most reliable empathy test according to Lawrence, Shaw, Baker, Baron-Cohen \& David (2004) and Baron-Cohen \& Wheelwright (2004). In the past, several tests had been used by psychologists even though empathy was not easy to measure. However, each earlier test had significant weaknesses and was used more for clinical purposes to identify psychological disorders. In 2003, Bacon-Cohen \& Wheelwright released the Empathy Quotient (EQ), which effectively measures empathy in both healthy and clinical populations who might have Asperger Syndrome or High Functioning Autism (Lawrence et al., 2004; Baron-Cohen \& Wheelwright, 2004). The EQ has been known as a popular self-report questionnaire of empathy (Batchelder, Brosnan \& Ashwin, 2017), and had been translated into 37 different languages (ARC, 2018). The Italian version of EQ research claimed the high 
reliability of the EQ (Preti, Vellante, Baron-Cohen, Zucca, Pretretto \& Masala, 2010). It indicates that there is a certain level of validity in the EQ.

The EQ is a self-report questionnaire with 40 questions (Appendix B) on a 4-point Likert scale (Lawrence et al., 2004): strongly agree, slightly agree, strongly disagree and slightly disagree. Each question scores 1 point for mild empathetic response, 2 points for strong empathetic response and 0 point for non-empathetic response (Baron-Cohen $\&$ Wheelwright, 2004). The questionnaire asks how a participant responds to other people's behavior or reaction, what kind of communication style a participant prefers, what kind of situation makes a participant upset or happy, and how a participant feels someone's feeling. I did not include 20 filler questions for this research because it was too long for the participants to answer two surveys, and 40 EQ questions were recommended for online presentation. According to Baron-Cohen \& Wheelwright (2004), 30 points out of 80 points is a cut-off for determining whether an individual likely has autism spectrum. If they score fewer than 30 points on the EQ, it means they have autism spectrum, and if they have more than 30 points, they are more likely to belong to the neurotypcial population.

\section{Data collection/Procedure}

In order to collect the data efficiently and promptly, I used a survey tool, Qualtrics, offered by Portland State University. I created a platform in the system, entering the two questionnaires: the Language History Questionnaire and the Empathy Quotient. The participants accessed the questionnaires by either an email invite or the link on the social network. The data collection was operated through Qualtrics. 
I reviewed and removed the inappropriate survey answers, and exported the data to Excel first and to SPSS. I used an Independent t-test to compare the means of the EQ scores between advanced and beginning language learners. I used a Spearman Rho correlation to check for a relationship between the EQ test scores and different categories: language proficiency, daily usage of L2, self-reported L2 speaker, gender, education level \& study abroad. 


\section{Results}

In my results, I did not observe significant differences between the advanced language learners and the low-level language learners in the empathy test, and there was no correlation between the empathy level and language proficiency, nor with other factors such as education level, overseas experiences, usage of L2, self-reported L2 speaker with the exception of gender. The results did not support my hypothesis.

First, I compared two groups with high and low level of language proficiency. I calculated the average proficiency score of each participant's level with a range of 1-7 (adding the scores of language skills, reading, speaking, writing and listening, and dividing by 4). There were 13 participants who were lower than the level 3 , which were considered as low-level language learners, and there were 27 participants who were higher than the level 6 , which were considered as advanced language learners. There were 16 participants who were between the level 4 and the level 5, and 23 participants who were between the level 5 and the level 6, which were considered as mid-level language learners. The mean empathy score of the group higher than 6 was 43.70, and the one of lower than 3 was 41.62 . I conducted an Independent t-test between those two groups, and there was no statistical significance; $\mathrm{t}(38)=0.55, \mathrm{p}>0.05$.

In addition to comparing two groups of the specific proficiency levels, I selected the top 10 of the highest proficient level and the lowest 10 proficient level participants in order to make each group exclusively high, which is the average of 6.95 proficiency, and low, which is the average of 1.73 proficiency. The average EQ score of each group was followed; the average EQ score of the highest 10 in terms of proficiency was 39.60 
points, and the lowest 10 was 41.60 points. There is no statistically significant difference between those two groups according to a t-test; $\mathrm{t}(18)=.441, \mathrm{p}>0.05$.

Table 3.1: Mean empathy scores by proficiency score

\begin{tabular}{|l|l|}
\hline Group by proficiency score & $\begin{array}{l}\text { Mean Empathy Score (Standard } \\
\text { Deviation) }\end{array}$ \\
\hline Proficiency score above 6 & $43.70(12.84)$ \\
\hline Proficiency score below 3 & $41.62(6.90)$ \\
\hline Top 10 & $39.60(12.77)$ \\
\hline Bottom 10 & $41.60(6.59)$ \\
\hline
\end{tabular}

The correlation between language proficiency and EQ score did not show significance; $\mathrm{r}=-0.081, \mathrm{p}=0.233>0.01$, nor was there any correlation with other factors such as education level, study abroad, self-reported L2 speaker and L2 usage per day.

However, the correlation between the EQ test and gender was statistically significant; the Spearman rho correlation coefficient between EQ and gender, was $\mathrm{r}=$ 0.264, 0.008, $\mathrm{p}<0.05$ (1-tailed). The mean of EQ score for males (n: 21) was 38.90, and the one for females (n: 58) was 46.93 (Table 3.2.). Some participants identified themselves as other, and the mean for other (n: 4) was 39.50, and they were excluded from this gender comparison because they were so few. The difference of the EQ score between female and male was 8.03. There was a statistically significant difference: $t$ $(77)=-2.96, \mathrm{p}<0.05$ (2-tailed). 
Table 3.2: Means of total Empathy Quotient (EQ) score across genders

\begin{tabular}{|l|l|l|}
\hline Gender & Mean of EQ score & Std. Deviation \\
\hline Male (n:21) & 38.90 & 9.61 \\
\hline Female (n:58) & 46.93 & 11.01 \\
\hline
\end{tabular}

As in Baron-Cohen \& Wheelwright (2014) suggest, my research had the same result as other researchers who compared empathy scores between males and females; females scored higher than males. However, there was no relationship between empathy level and language proficiency. 


\section{Discussion}

The results of my research did not support my hypothesis; the advanced proficient language learners in my research did not show higher level of empathy than the low proficient learners. In addition, there was no relationship between empathy level and other factors such as the usage of L2 per day, experience of studying abroad, and selfreported L2 speaker. However, one factor did show a significant difference in empathy scores: the difference between males and females in empathy level. Perhaps the relationship between language proficiency and empathy in adults is more complicated than it is in children.

When I started this project, I reviewed Zelazo's research (2014) about the relationship between children's executive function and empathy. I realized that many other researchers had examined executive function in bilingual children and agreed that bilingual children have higher executive function skills when compared to monolingual children (Bialystok \& Viswanathan, 2009; Yang, Yang \& Lust, 2011; Costa, Hernandez, Costa-Faidella \& Sebastian-Gilles, 2009) as well as bilingual adults (Costa, Hernandez, Costa-Faidella \& Sebastian-Galles, 2009; Woodniecka, Crank, Luo \& Bialystok, 2010). The researchers mainly focused on discussing which factors most influenced executive function in bilingual children, and if the influential factors could be socio-economic status, ethnic and cultural background, or even individual differences (Yang, Yang \& Lust, 2011). The research on children has only examined the relationship between bilingualism and executive functioning or the relationship between executive functioning and empathy, but not all three of them. Additionally, Zelazo (2014) claimed that three 
aspects of executive function, cognitive function, working memory and inhibition control, would influence the development of empathy, and the level of executive function in childhood could predict the level of self-social awareness, school readiness, academic achievement and other developmental outcomes into adulthood. Those three aspects of executive functioning are all cognitive skills that both adults and children could learn. He suggested the interventions with children on those executive function skills integrated with reflection practice would help them develop empathy, which meant possibly the interventions could work well for adults to develop empathy. Consequently, from that research, I hypothesized that bilingual children should have higher empathy levels than monolingual children because bilingual children have higher executive functioning (Bialystok \& Viswanathan, 2009; Bialystok \& Barac, 2012), and furthermore, I inferred from this research that bilingual adults (who also have higher executive function skills than monolinguals) should have higher empathy as well. Since I did not directly examine executive functioning in my participants, I cannot confirm whether the highly proficient language learners had high executive function or not. Furthermore, there is no research on the relationship between empathy and adults who have high executive function. However, since my research results did not find any relationship between language proficiency and empathy in adult learners, I must conclude that there were other factors that affected adults' empathy levels, or these adult highly proficient language learners did not have the advantage in executive functioning even though other populations of adult bilinguals have been shown to have an advantage (Costa, Hernandez, Costa-Faidella \& Sebastian-Galles, 2009; Woodniecka, Crank, Luo \& Bialystok, 2010). 
If Zelazo's research with children is extrapolated, it is still possible adult bilinguals who have high executive function might have higher empathy levels, which implies that as long as people are able to develop their executive function, they are likely to develop their level of empathy too. However, in order to confirm my hypothesis, more research about executive function in adults is required, and research is needed to test the relationship between bilingual adults and empathy.

\section{Limitations}

One limitation of this study may be the instruments I used for language assessment and empathy level; they may not have been sufficient to collect accurate data.

For language proficiency assessment, I could have included a more objective proficiency test such as TOEFL or IELTS in addition to the Language History Questionnaire (LHQ). I choose the LHQ because it was easy to administer via a survey. However, the validity of self-ratings of language proficiency is questionable since we do not know in which scale each participant uses to evaluate their own level. According to the research of self-ratings of language proficiency in bilinguals between different language populations, Chinese-English bilinguals scored higher than Spanish-English bilinguals (Thomoschuk, Ferreira \& Collan, 2019), which implies different language and cultures might influence self-ratings. For my research, I had fifteen Japanese participants who might have evaluated their language proficiency lower than the actual levels because Japanese participants have a tendency toward a self-critical attitude (Heine, Kitayama \& Lehman, 2001). Using only the LHQ might not be enough to evaluate their language 
proficiency level objectively and accurately because the LHQ, a self-rated test, could be subjective.

There is also an issue with the empathy test. The EQ test was designed to check whether people were autistic or not, and at the same time check their empathy level. According to Baron-Cohen \& Wheelwright (2004), 30 points out of 80 points is the cutoff for determining whether an individual likely has autism. If someone scores fewer than 30 points on the EQ, it means they are likely to be on the autism spectrum, and if they have more than 30 points, they are more likely to belong to the neurotypcial population. My research had 77 out of 83 participants who scored higher than 30 points on the EQ, which means that most of the participants belonged to the non-autistic population. Because the EQ was designed to distinguish individuals with autism from those without autism, it is possible that the questions on the EQ are not effective in distinguishing subtle differences among the non-autistic participants. Moreover, the EQ was designed by UK scholars, and has been translated into mainly European languages and has mostly been used in Europe. It also has been translated in Chinese and Korean. There was research to check validation of the EQ in Chinese (Zhao et al., 2017) and in Korean (Kim \& Lee, 2010). Both of them confirmed validation of the EQ; however, they pointed out the limitations that the questionnaire was developed in Western culture. The questions may not be relevant to some of my participants since there were 15 Japanese participants, and their scores of EQ might be affected. The EQ may not be applied cross-culturally.

In order to address the limitation related to measuring empathy, as an alternative test, possibly I could use the Intercultural Development Inventory (IDI) to check how far 
the participants achieve intercultural competence that is connected to empathy. Bennett and Ikeda (1998 as cited in Bennett, Bennett \& Allen, 2013) illustrated the typical fit between language proficiency levels and developmental levels of intercultural sensitivity based on the Developmental Model of Intercultural Sensitivity (DMIS); students in lower level language proficiency are likely to be at Denial/Defense stage; intermediate level students are more likely to be at Minimization/Acceptance, and advanced students are at Adaptation/Integration. This framework shows that language learning affects one factor related to empathy, intercultural competence, and the IDI could be a useful indirect measurement of empathy.

\section{Suggestions for future research}

I hypothesized that bilingual adults should have high levels of empathy because they have high executive function. My study was the first to test this prediction. Unfortunately, my data did not support this hypothesis. However, I assumed that high language proficiency equaled high executive function. I did not test whether the adult bilinguals had high executive function directly, and so this raises a number of questions. Do highly proficient second language learners have higher executive function than low proficient second language learners? Do adult bilinguals have higher executive function when compared to their monolingual peers? Alternatively, is there a difference between highly proficient language learners and people who are bilingual from an early age in terms of executive function? Maybe the bilingual learners are also bicultural in a way that second language learners are not, and highly proficient language learners may not have the same kind of high executive function. 
In order to address those questions, I suggest testing whether highly proficient language learners have high executive function or not, and also do more research with adult bilinguals to confirm if they have high executive function, and finally test empathy in adult bilinguals.

My research coheres with other research that has found that females score higher on the empathy scales when compared to males (Baron-Cohen \& Wheelwright, 2004; Lawrence, Shaw, Baker, Baron-Cohen \& David, 2004), as the females in my research had significantly higher scores than the males. Baron-Cohen \& Wheelwright (2004) suggest that the reason why men have lower empathy level could be that their brain is defined as individuals who are more systemizing than empathizing, and the female brain is defined as more empathizing than systemizing. Christov-Moore et al. (2014) give some examples and other possible explanations for the difference between two genders. There might be cultural and social expectations about gender roles, whereas non-human animals such as primates show evidence that sex differences in empathy has biological roots, especially, in the core of empathy, the practice of caregiving. However, the gender topic needs more discussion because we do not know where these differences come from, and furthermore, there are also people who do not belong to a binary gender in society, and gender roles continue to change. The gender question needs to include the participants' identities, too.

\section{Conclusion}

As a conclusion, my hypothesis about the relationship between language proficiency and empathy scores was not confirmed; however, it was a good start for studying empathy and the relationship between empathy and language learning. I 
reconfirmed that empathy has multiple factors and that it is extremely difficult to understand its relationship with other elements. Empathy is deeply connected to psychological, social, cultural and cognitive aspects. Language learning is impacted by many factors as well, and it is difficult to determine what factors most influence the language learning process. Furthermore, examining the relationship between empathy and executive function in adults would move forward to the next level in empathy research.

Learning is a human positive behavior or action that can be obtained from selfreflection, repetition, experience and exercise. It is a cognitive process that human beings enhance from their interaction with others. Particularly language learning is not just learning an academic subject, but more like learning with a package of culture, people and society. Language learning is the first step to understanding a person as a whole human-being. Without learning their language, it is impossible to understand a person and have real authentic communication with other people. If there is no communication with compassion and empathy in our living world, how can we live peacefully, accepting differences and being accepted by others, and find a collaborative solution? Being a global citizen or being interculturally competent requires understanding what empathy is, and actively looking for someone's path even though the process is sometimes painful. Language comes with feelings, and feeling comes with language. Language and feeling are expressed together as one form in order to have effective and powerful communication between people. 
References

ACTFL Proficiency Guidelines 2012.

https://www.actfl.org/sites/default/files/pdfs/public/ACTFLProficiencyGuidelines 2012_FINAL.pdf.

Assigning CEFR Ratings to ACTFL Assessments.

https://www.actfl.org/sites/default/files/reports/Assigning_CEFR_Ratings_To_A CTFL_Assessments.pdf

Autism Research Centre. (2018). https://www.autismresearchcentre.com/arc tests

Batchelder, L., Brosnan, M., \& Ashwin, C. (2017). The development and validation of the empathy components questionnaire (ECQ). Plos One, 12 (1). https://doi.org/10.1371/journal.pone.0169185

Baron-Cohen, S., \& Wheelwright, S. (2004). The empathy quotient: An investigation of adults with Asperger syndrome or high functioning autism, and normal sex difference. Journal of Autism and Developmental Disorders, Vol.34, No.2. Plenum.

Bennett, J. M. (2014). Intercultural competence: Vital perspectives for diversity and inclusion. In B.M. Ferdman \& B. Deane (Eds.), Diversity at Work: The Practice of Inclusion (pp. 155-176). Wiley/Jossey-Bass. https://doi.org/10.1002/9781118764282.ch5 
Bennett, J.M., Bennett, M. J. \& Allen, W. (2003). Developing intercultural competence in the language classroom. In D. L. Lange \& R.M. Lange (Eds.), Culture as a Core: Perspectives on Culture in Second Language Learning (pp.237-270). Greenwich, Conn. : Information Age Pub.

Bennett, M. J. (1986). A developmental approach to training for intercultural sensitivity. International Journal of Intercultural Relations, vol. 10, pp. 179-196. Pergamon Journals Ltd.

Bennett, M. J. (1998). Intercultural communication: A current perspective. In M.J. Bennett (Ed.), Basic concepts of intercultural communication, selected readings (1-34). Intercultural Press, Inc.

Berwick, R., Friederici, A., Chomsky, N., \& Bolhuis, J. (2012). Evolution, brain, and the nature of language. Trends in Cognitive Sciences, 17 (2). Elsevier.

Bialystok, E., \& Viswanathan, M. (2009). Components of executive control with advantages for bilingual children in two cultures. Cognition, 112, 494-500.

Bialystok, E., \& Barac, R. (2012). Emerging bilingualism: Dissociating advantages for metalinguistic awareness and executive control. Cognition, 122, 1, 67-73.

Boroditsky, L. (2011). How language shapes thought: the languages we speak affect our perceptions of the world. Cognitive Psychology, Feb 2011. Scientific American. 
Brady, D., Saklofske, D., Schwean, V., Montogomery, J., Thorne, K., \& McCrimmon, A. (2017). Executive functions in young adults with autism spectrum disorder. Focus on Autism and Other Developmental Disabilities, vol. 32 (1), pp. 31-43.

Chen, GM. (2010). The impact of intercultural sensitivity on ethnocentrism and intercultural communication apprehension. Intercultural Communication Studies, 19 (1), 1-9. University of Rhode Island.

Christov-Moore, L., Simpson, E.A., Coude, G., Griagaityte, K., Iacoboni, M., \& Ferrari, P. (2014). Empathy: Gender effect in brain and behavior. Neuroscience and Biobehavioral Reviews, 46, pp. 604-627.

Cognition (n.d.). Retrieved December 1, 2018 from Wikipedia: https://en.wikipedia.org/wiki/CognitionCosta, A., Hernandez, M., Costa-Faidella, J., \& Sebastian-Galles, N. (2009). On the bilingual advantage in conflict processing: Now you see it, now you don't. Cognition. 113, 135-140. Elsevier. https://dx.doi.org/10.1016/j.cognition.2009.08.001.

Deardorff, D. (2006). Identification and assessment of intercultural competence as a student outcome of internationalization. Journal of Studies in International Education, vol. 10 No. 3, Fall 2006, pp. 241-266. Association for Studies in International Education.

Dewaele, JM., \& Wei, L. (2012). Multilingualism, empathy and multicompetence. International Journal of Multilingualism, 9:4, pp. 352-366. Routledge. 
Eun, B. \& Lim, H-S. (2009). A sociocultural view of language learning: The importance of meaning-based instruction. TESL Canada Journal, vol. 27. No. 1, Winter 2009, pp. 13-26.

Fan, S., Liberman, Z., Keysar, B., \& Kinzler, K. (2015). The exposure advantage: Early exposure to a multilingual environment promotes effective communication. Psychological Science, vol. 26 (7), pp. 1090-1097.

Ganschow, L., Sparks, R., Anderson, R., Javorshy, J., Skinner, S., Patton, J. (1994). Difference in language performance among high-, average-, and low- anxious college foreign language learners. The Modern Language journal, vol. 78, 1, pp. 41-55. Wiley.

Grosjean, F. (2015). Bicultural bilinguals. International Journal of Bilingualism, Vol 19, (5), 572-586. Sage. http://journals.sagepub.com/doi/abs/10.1177/1367006914526297

Grosjean, F. (2013). Bilingualism: A short introduction. In F. Grosjean \& P. Li (Eds.), The Psycholinguistics of Bilingualism (pp. 5-25). UK: Wiley-Blackwell.

Grosjean, F. (1998). Studying bilinguals: Methodological and conceptual issues. Bilingualism: Language and Cognition, 1, 131-149. Cambridge University Press.

Gruhn, D., Reucal, K., Diehl, M., Lumley, M., \& Labouvie-Vief, G. (2008). Empathy across the adult lifespan: Longitudinal and experience-sampling findings. Emotion, 8 (6), 753-765. http://psycnet.apa.org/doi/10.1037/a0014123 
Hammer, M. R., Bennett, M. J., \& Wiseman, R. (2003). Measuring intercultural sensitivity: The intercultural development inventory. International Journal of Intercultural Relations, 27, pp. 421-443.

Harris, C. L. (2006). Language and cognition. Gallery

Heine, S., Kitayama, S. \& Lehman, D. (2001). Culutural differences in self-evaluation Japanese readily accept negative self-relevant information. Journal of CrossCultural Psychology, vol. 32, No 4, pp. 434-443.

Herlin, I., \& Visappa, L. (2016). Dimensions of empathy in relation to language. Nordic Journal of linguistics, 29, 2, 135-157. Cambridge University Press. https://doi.org/10.1017/S0332586516000111

Huang, S. C., \& Tsai, R. R. (2003). A comparison between high and low English proficiency learners' beliefs. ERIC.

Intercultural Development Inventory (2019). Retrieved from https://idiinventory.com/

Kim, J., \& Lee, S. J. (2010). Reliability and validity of the Korean version of the empathy quotient scale. Psychiatry investigation, 7(1), 24-30. doi:10.4306/pi.2010.7.1.24.Language (n.d.). In Encyclopedia Britannica online. Retrieved from https://www.britannica.com/topic/language

Lantolf, J. \& Thorne, S. L. (2007). Sociocultural theory and second language learning. In B. Van Patten \& J. Williams (Eds.), Theories in second language acquisition An introduction (pp. 201-224). New York: Routledge. 
Lantolf, J., Thorne, S. L., \& Poehner, M. (2015). Sociocultural theory and second language development. In B. Van Patten \& J. Williams (Eds.), Theories in second language acquisition (pp. 207-226). New York: Routledge.

Lawrence, E. J., Shaw, P., Baker, D., Baron-Cohen, S., \& David, A.S. (2004). Measuring empathy: reliability and validity of the empathy quotient. Psychological Medicine, 34, 911-924. Cambridge University Press.

Lemetyinen, H. (2012). Language acquisition. Simply Psychology. Retrieved from https://www.simplypsychology.org/language.html

Li, P., Sepanski, S., \& Zhao, X. (2006). Language history questionnaire: A web-based interface for bilingual research. Behavior Research Methods, 38 (2), 202-210.

Luk, G., \& Bialystok, E. (2013). Bilingualism is not a categorical variable: Interaction between language proficiency and usage. Journal of Cognitive Psychology, 25 (5), 605-621. https://doi.org/10.1080/20445911.2013.795574

McLeod, S. (2018). Lev Vygotsky. Simply Psychology. Retrieved from https://www.simplypsychology.org/vygotsky.html

Moeller, A., \& Catalanao, T. (2015). Foreign language teaching and learning. International Encyclopedia for Social and Behavioral Science, vol. 9, pp. 327332. University of Nebraska - Lincoln.

Morley, J. (1991). The pronunciation component in teaching English to speakers of other languages. TESOL Quarterly, vol.25, No.3, 481-520. TESOL. 
Ortega, L. (2007). Second language learning explained? SLA across nine contemporary theories. In B. Van Patten \& J. Williams (Eds.), Theories in Second Language Acquisition, An Introduction, pp. 225-250. New York: Routledge.

Perlovsky, L., \& Sakai, K. L. (2014). Language and cognition. Frontiers in Behavioral Neuroscience, 8 (436). https://dx.doi.org/10.3389\%2Ffnbeh.2014.00436

Preti, A., Vellante, M., Baron-Cohen, S., Zucca, G., Petretto D. R., \& Masala, C. (2010). The empathy quotient: A cross-cultural comparison of the Italian version. Cognitive Neuropsychiatry, 16 (1), 50-70. Routledge.

Roots of Empathy. http://rootsofempathy.org/

Surrain, S., \& Luk, G. (2017). Describing bilinguals: A systematic review of labels and descriptions used in the literature between 2005 - 2015. Bilingualism: Language and Cognition. 1-15. https://doi.org/10.1017/S1366728917000682

Tomoschuk, B., Ferreira, V. \& Gollan, T. (2019). When a seven is not a seven: self-rating of bilingual language proficiency differ between and within language populations. Bilingualism: Language and Cognition, 22 (3), 516-536. https://doi.org/10.1017/S1366728918000421

Ushida, E. \& Dornyei, Z. (2012). Motivation. In S.M. Gass \& A. Mackey (Eds.), The Routledge handbook of second language acquisition, pp.396-409. New York: Routledge. 
Walter, H. (2012). Social cognitive neuroscience of empathy: concepts, circuits, and genes. Emotion Review, vol.4. No. 1, 9-17. SAGE Publishing.

Widdowson, H.G. (1994). The ownership of English. TESOL Quarterly, Vol.28, No.2, 377-389. TESOL.

Wondniecka, Z., Craik, F.I.M., Luo, L., \& Bialystok, E. (2010). Does bilingualism help memory? Competing effects of verbal ability and executive control. International Journal of Bilingual Education and Bilingualism, Vol. 13, No.5, pp. 575-595.

Yamagata-Lynch, L.C. (2010). Understanding cultural historical activity theory. Activity Systems Analysis Methods: Understanding Complex Learning Environments, ch.2. https://doi.org/10.1007\%2f978-1-4419-6321-5_2

Yang, S., Yang, H., \& Lust, B. (2011). Early childhood bilingualism leads to advances in executive attention: Dissociating culture and language. Bilingualism: Language and Cognition, 14 (3), 412-422. Cambridge University Press. https://doi.org/10.1017/S1366728910000611

Zelazo, P.D. (2014). Executive function, reflection, and neuroplasticity: Implications for promoting empathy in childhood. Proceedings from Roots of Empathy: Research Symposium 2014. pp. 3-4.

Zelazo, P.D., Blair, C.B., \& Willoughby, M.T. (2016). Executive function: implications for education. National Center for Education Research, NCER 2017-2000, Washington, DC: Institute of Education Sciences, U.S. Department of Education. 
Zhao, Q., Neumann, D., Cao, X., Baron-Cohen, S., Sun, X., Cao, Y., Shum, D. (2017). Validation of the empathy quotient in mainland China. Journal of Personal Assessment. http://dx.doi.org/10.1080/00223891.2017.1324458 


\section{Appendix A}

\section{Language History Questionnaire (Modified by Mika Sakai)}

Your age?

- $\quad$ Between $15-20$

- $\quad$ Between $21-30$

- $\quad$ Between $31-40$

- $\quad$ Between $41-55$

- $\quad$ Over 56

Your gender?

- $\quad$ Male

- $\quad$ Female

- Other

Highest Education?

- $\quad$ High School

- 2 year college

- 4 year college

- Master degree

- $\quad \mathrm{PhD}$

- $\quad$ Other

County of Origin 
Q1. Which language did you learn as your first language?

Q2. Are you a speaker of choice of Q1?

- Yes

- $\quad$ No

Q3. What language have you learned or are you learning as a second language?

Q4. Are you a speaker of Q3?

- Yes

- $\quad$ No

Q5. Do you plan to continue to study choice of Q3?

- $\quad$ Yes

- Maybe

- No

Q6. Do you speak any other languages?

- $\quad$ Yes

- $\quad$ No

Q7. List the other language(s) you speak here, along with self-assessment of your proficiency (beginner, intermediate, advanced). 
Q 8. Have you studied abroad?

- Yes

- $\quad$ No

Q 9. Where did you study and for how long? List each study abroad experience separately.

Q 10. Have you undertaken any extended travel (over 6 weeks) or sojourn abroad?

- Yes

- No

Q 11. Please list the extended travel experiences you have had (country/countries) and the amount of time.

Q12. Have you ever taken a proficiency test in your second language?

- Yes

- $\quad$ No

Q 13. What were the results of the test for (e.g. TOEFL score, CEF level, ACTFL level, or IELTS band score)?

Q 14. How have you learned your other language up to this point? Choose all that apply.

- Mainly through formal classroom instruction

- $\quad$ Mainly through interacting with people

- $\quad$ Mixture of both (formal and informal) 
- $\quad$ Social Media/Online

- Other

Q 15. Reading - List all foreign languages you know in order of most proficient to least proficient. Rate your ability for reading in each language.

Very Poor Poor Fair Functional Good Very Good Native-like

Language 1

Language 2

Language 3

Q 16. Speaking - List all foreign languages you know in order of most proficient to least proficient. Rate your ability for speaking in each language.

Very Poor Poor Fair Functional Good Very Good Native-like

Language 1

Language 2

Language 3

Q 17. Writing - List all foreign languages you know in order of most proficient to least proficient. Rate your ability for writing in each language.

Very Poor Poor Fair Functional Good Very Good Native-like

Language 1

Language 2

Language 3

Q 18. Listening - List all foreign languages you know in order of most proficient to least proficient. Rate your ability for listening in each language.

Very Poor Poor Fair Functional Good Very Good Native-like

Language 1

Language 2

Language 3 
Q 19. What language do you usually speak at home?

- $\quad$ English

- Other

- Both

Q 20. What language or languages do your/did your parents usually speak to each other at home?

- $\quad$ English

- Other

- Both

Q 21. In which language(s) do you usually dream?

- $\quad$ English

- Other

- Both

Q 22. Among the languages you know, which language is the one that you would prefer to use at home?

Q 23. Among the languages you know, which language is the one that you would prefer to use at work/school?

Q 24. Among the languages you know, which language is the one that you would prefer to use at a party? 
Q 25. Among the languages you know, which language is the one that you would prefer to use in general?

Q 26. Estimate, in terms of percentages, how much you use your first language and other languages per day (in all daily activities combined) - Total should be $100 \%$.

$$
\begin{array}{llllllllll}
10 & 20 & 30 & 40 & 50 & 60 & 70 & 80 & 90 & 100
\end{array}
$$

Your First Language

Your Second Language

Other Language(s) 
Appendix B

S. Baron-Cohen and S. Wheelwright, (2004) Empathy Quotient with scoring

Responses that score 1 or 2 points are marked. Other responses score 0. For total score, sum all items.

\begin{tabular}{|c|c|c|c|c|c|}
\hline & & $\begin{array}{l}\text { strongly } \\
\text { agree }\end{array}$ & $\begin{array}{l}\text { slightly } \\
\text { agree }\end{array}$ & $\begin{array}{l}\text { slightly } \\
\text { disagree }\end{array}$ & $\begin{array}{l}\text { strongly } \\
\text { disagree }\end{array}$ \\
\hline 1. & $\begin{array}{l}\text { I can easily tell if someone else wants } \\
\text { to enter a conversation. }\end{array}$ & 2 & 1 & & \\
\hline 2. & $\begin{array}{l}\text { I find it difficult to explain to others } \\
\text { things that I understand easily, when } \\
\text { they don't understand it first time. }\end{array}$ & & & 1 & 2 \\
\hline 3. & I really enjoy caring for other people. & 2 & 1 & & \\
\hline 4. & $\begin{array}{l}\text { I find it hard to know what to do in a } \\
\text { social situation. }\end{array}$ & & & 1 & 2 \\
\hline 5. & $\begin{array}{l}\text { People often tell me that I went too far } \\
\text { in driving my point home in a } \\
\text { discussion. }\end{array}$ & & & 1 & 2 \\
\hline 6. & $\begin{array}{l}\text { It doesn't bother me too much if I am } \\
\text { late meeting a friend. }\end{array}$ & & & 1 & 2 \\
\hline 7. & $\begin{array}{l}\text { Friendships and relationships are just } \\
\text { too difficult, so I tend not to bother } \\
\text { with them. }\end{array}$ & & & 1 & 2 \\
\hline 8. & $\begin{array}{l}\text { I often find it difficult to judge if } \\
\text { something is rude or polite. }\end{array}$ & & & 1 & 2 \\
\hline 9. & $\begin{array}{l}\text { In a conversation, I tend to focus on } \\
\text { my own thoughts rather than on what } \\
\text { my listener might be thinking. }\end{array}$ & & & 1 & 2 \\
\hline 10. & $\begin{array}{l}\text { When I was a child, I enjoyed cutting } \\
\text { up worms to see what would happen. }\end{array}$ & & & 1 & 2 \\
\hline 11. & $\begin{array}{l}\text { I can pick up quickly if someone says } \\
\text { one thing but means another. }\end{array}$ & 2 & 1 & & \\
\hline
\end{tabular}




\begin{tabular}{|c|c|c|c|c|c|}
\hline & & $\begin{array}{l}\text { strongly } \\
\text { agree }\end{array}$ & $\begin{array}{l}\text { slightly } \\
\text { agree }\end{array}$ & $\begin{array}{l}\text { slightly } \\
\text { disagree }\end{array}$ & $\begin{array}{l}\text { strongly } \\
\text { disagree }\end{array}$ \\
\hline 12. & $\begin{array}{l}\text { It is hard for me to see why some } \\
\text { things upset people so much. }\end{array}$ & & & 1 & 2 \\
\hline 13. & $\begin{array}{l}\text { I find it easy to put myself in } \\
\text { somebody else's shoes. }\end{array}$ & 2 & 1 & & \\
\hline 14. & $\begin{array}{l}\text { I am good at predicting how someone } \\
\text { will feel. }\end{array}$ & 2 & 1 & & \\
\hline 15. & $\begin{array}{l}\text { I am quick to spot when someone in a } \\
\text { group is feeling awkward or } \\
\text { uncomfortable. }\end{array}$ & 2 & 1 & & \\
\hline 16. & $\begin{array}{l}\text { If I say something that someone else is } \\
\text { offended by, I think that that's their } \\
\text { problem, not mine. }\end{array}$ & & & 1 & 2 \\
\hline 17. & $\begin{array}{l}\text { If anyone asked me if I like their } \\
\text { haircut, I would reply truthfully, even } \\
\text { if I didn't like it. }\end{array}$ & & & 1 & 2 \\
\hline 18. & $\begin{array}{l}\text { I can't always see why someone } \\
\text { should have felt offended by a remark. }\end{array}$ & & & 1 & 2 \\
\hline 19. & $\begin{array}{l}\text { Seeing people cry doesn't really upset } \\
\text { me. }\end{array}$ & & & 1 & 2 \\
\hline 20. & $\begin{array}{l}\text { I am very blunt, which some people } \\
\text { take to be rudeness, even though this } \\
\text { is unintentional. }\end{array}$ & & & 1 & 2 \\
\hline 21. & $\begin{array}{l}\text { I don't tend to find social situations } \\
\text { confusing }\end{array}$ & 2 & 1 & & \\
\hline 22. & $\begin{array}{l}\text { Other people tell me I am good at } \\
\text { understanding how they are feeling } \\
\text { and what they are thinking. }\end{array}$ & 2 & 1 & & \\
\hline 23. & $\begin{array}{l}\text { When I talk to people, I tend to talk } \\
\text { about their experiences rather than my } \\
\text { own. }\end{array}$ & 2 & 1 & & \\
\hline 24. & It upsets me to see animals in pain. & 2 & 1 & & \\
\hline 25. & $\begin{array}{l}\text { I am able to make decisions without } \\
\text { being influenced by people's feelings. }\end{array}$ & & & 1 & 2 \\
\hline
\end{tabular}




\begin{tabular}{|c|c|c|c|c|c|}
\hline & & $\begin{array}{l}\text { strongly } \\
\text { agree }\end{array}$ & $\begin{array}{l}\text { slightly } \\
\text { agree }\end{array}$ & $\begin{array}{l}\text { slightly } \\
\text { disagree }\end{array}$ & $\begin{array}{l}\text { strongly } \\
\text { disagree }\end{array}$ \\
\hline 26 & $\begin{array}{l}\text { I can easily tell if someone else is } \\
\text { interested or bored with what I am } \\
\text { saying. }\end{array}$ & 2 & 1 & & \\
\hline 27 & $\begin{array}{l}\text { I get upset if I see people suffering on } \\
\text { news programmes. }\end{array}$ & 2 & 1 & & \\
\hline 28 & $\begin{array}{l}\text { Friends usually talk to me about their } \\
\text { problems as they say I am very } \\
\text { understanding. }\end{array}$ & 2 & 1 & & \\
\hline 29. & $\begin{array}{l}\text { I can sense if I am intruding, even if } \\
\text { the other person doesn't tell me. }\end{array}$ & 2 & 1 & & \\
\hline 30. & $\begin{array}{l}\text { People sometimes tell me that I have } \\
\text { gone too far with teasing. }\end{array}$ & & & 1 & 2 \\
\hline 31. & $\begin{array}{l}\text { Other people often say that I am } \\
\text { insensitive, though I don't always see } \\
\text { why. }\end{array}$ & & & 1 & 2 \\
\hline 32. & $\begin{array}{l}\text { If I see a stranger in a group, I think } \\
\text { that it is up to them to make an effort } \\
\text { to join in. }\end{array}$ & & & 1 & 2 \\
\hline 33. & $\begin{array}{l}\text { I usually stay emotionally detached } \\
\text { when watching a film. }\end{array}$ & & & 1 & 2 \\
\hline 34. & $\begin{array}{l}\text { I can tune into how someone else feels } \\
\text { rapidly and intuitively. }\end{array}$ & 2 & 1 & & \\
\hline 35 & $\begin{array}{l}\text { I can easily work out what another } \\
\text { person might want to talk about. }\end{array}$ & 2 & 1 & & \\
\hline 36. & $\begin{array}{l}\text { I can tell if someone is masking their } \\
\text { true emotion. }\end{array}$ & 2 & 1 & & \\
\hline 37. & $\begin{array}{l}\text { I don't consciously work out the rules } \\
\text { of social situations. }\end{array}$ & 2 & 1 & & \\
\hline 38. & $\begin{array}{l}\text { I am good at predicting what someone } \\
\text { will do. }\end{array}$ & 2 & 1 & & \\
\hline
\end{tabular}




\begin{tabular}{|l|l|c|c|c|c|}
\hline & $\begin{array}{l}\text { strongly } \\
\text { agree }\end{array}$ & $\begin{array}{l}\text { slightly } \\
\text { agree }\end{array}$ & $\begin{array}{l}\text { slightly } \\
\text { disagree }\end{array}$ & $\begin{array}{l}\text { strongly } \\
\text { disagree }\end{array}$ \\
\hline 40. & $\begin{array}{l}\text { I can usually appreciate the other } \\
\text { person's viewpoint, even if I don't } \\
\text { agree with it. }\end{array}$ & 2 & 1 & & \\
\hline
\end{tabular}

